\title{
Living wills: anticipatory decisions and advance directives
}

Charles A Erin and John Harris The Centre for Social Ethics and Policy. University of Manchester, Manchester. UK

\section{Introduction}

There currently appears to be a ground swell of support in the United Kingdom and elsewhere in Europe and in North America for instituting some form of legal protection for anticipatory decisions. This would be a device for the delineation of the wishes in various matters of a person when compos mentis so that these wishes may be respected in the event that that person suffers a loss of mental competence. Here we will consider the major devices currently being evaluated in the UK which have their counterparts elsewhere, the so called 'living will' and the advance directive, both of which serve to protect anticipatory decisions. Perhaps the most obvious application of such devices is to mentally incapacitating conditions often associated with old age. However, it should not be forgotten that there are several conditions, such as AIDS, which can involve an end-stage loss of competence and can affect persons of all ages.

Address for correspondence: Charles A Erin, The Centre for Social Ethics and Policy, University of Manchester, Humanities Building, Oxford Road, Manchester M13 9PL, UK.

\section{Terminology}

'Living will' and 'advance directive' are terms whose meanings are often conflated. Whether this is a serious problem is a moot point: where the meanings of each coincide is in the notion of the anticipatory decisions of a competent person being recorded in advance of certain contingencies in the expectation that those decisions will be given weight upon those contingencies. However, both terms are terms of art and we might be well advised to look to what distinguishes them rather than to their common ground. According to the British Medical Association (BMA), 'advance directive' is a wider concept. ${ }^{1}$ It refers to a device whereby a mentally competent, adult person makes a written statement laying out his wishes in regard of various matters in the event that he loses his mental competence and thus his capacity for decision making. Assuming advance directives are in some sense just that - directives - and hence are given some level of validity, they will thus constitute his instructions. In the BMA's view, the living will differs from the advance directive in that:

The 'living will' has a similar aim but whereas an advance directive can give instructions about any decision and can request as well as refuse specific 
treatments, the living will is essentially a formal declaration by a competent adult conveying his wish for any life-prolonging measures to be withheld in circumstances where there is no prospect of recovery. ${ }^{1}$

Now, the advance directive is most often quoted in connection with decisions about medical treatment, particularly the treatment which might be provided as the patient approaches death'. ${ }^{1}$ However, it may embrace 'any matter upon which the individual has decided views'. ${ }^{1}$ And this is where, for the BMA, the distinction between the two devices lies.

This is just a stipulation on the part of the BMA and for all practical purposes there is simply no point in distinguishing between living wills and advance directives because they inevitably will be conflated. It is better, surely, to talk about different types of living will and different types of advance directive with different sorts of effects and intentions. Whilst it would seem that in the majority of cases any contrast between living wills and advance directives, so characterized, will fade from view, we will concentrate on the device which has the wider purview and our focus here will be advance directives. As we will use it, 'advance directive' will subsume 'living will'.

\section{Moral principles}

There is a very clear sense in which advance directives are an extension of informed consent doctrine and thus rely, as does informed consent, on the principle of respect for personal autonomy. Since the now famous Karen Quinlan case in the USA in $1976,{ }^{2}$ potential and actual patients, family members, and health care professionals appear ready to accept that treatment of incompetent patients should be guided by respect for the wishes of the patient as expressed prior to loss of competence. ${ }^{3-7}$ In the present context, the principle of respect for autonomy serves to safeguard the right to self-determination of the patient, and hence, by implication, 'competence' here refers to the capacity to make autonomous choices.

From the standpoint of the health care professional, there is often significant tension between respect for patient autonomy and the principles of nonmaleficience, beneficence, and justice. However, in this area there need be no great conflict between doing no harm (or, where one cannot do no harm, doing the least harm), doing good for others, and acting fairly on the one hand, and respecting the informed decisions of the patient on the other.

Where there is disagreement and the potential for dilemmas of conscience, the crucial question is as to whether or not prospective patients' wishes should be respected and, if so, in what form they require to be expressed for them to be valid and legitimate. And this is where institutional guidelines and the law come into play.

\section{Society's interests and the presumption in favour of intervention}

As a result of the Nancy Cruzan case, ${ }^{8,9}$ the United States Supreme Court upheld the Missouri Supreme Court's ruling that the State has an interest in preserving life which, without 'clear and convincing evidence' of the incompetent patient's previously expressed wishes (oral statements made to family members, for example, are insufficient evidence of one's wishes - and this is also the BMA's view ${ }^{1}$ ) should override any supposed right of the incompetent patient to decide in advance that life-sustaining treatment should be withheld or withdrawn. This ruling establishes as the 'default view' of society (in the USA at least) the assumption that citizens would wish their lives to be sustained in any event, even where there is no prospect of that 'life' supporting consciousness and hence constituting the sort of life that can in any meaningful sense be led and hence of any value to the individual whose life it was. This in fact conflicts radically with evidence which suggests that the vast majority of people would wish life-sustaining treatment withdrawn in certain situations such as loss of competence and the end stages of a terminal illness. ${ }^{10,11}$

In view of such evidence, it might be argued that we should perhaps establish as the default position that, under circumstances of irreversible loss of competence, life-sustaining treatment be withheld from all patients in the absence of advance directives to the contrary. We think not. If advance directives are to be taken seriously, it is implicit that the principle of autonomy of persons overrides any absolutist view of the sanctity of life. However, at the practical level, instituting a 
general policy of nontreatment of the incompetent would likely cause such anxiety among the competent (that, for example, on the approach of loss of competence they would be used as 'organ banks') as to distort the doctor-patient relationship and to undermine confidence in the impartiality of medicine and of society.

Maintaining the assumption that patients would, ceteris paribus, wish health care professionals to strive to keep them alive could, nonetheless, be said to err on the side of caution. However, if the currently respected right of patients to determine what will happen to their own bodies is to be consistently maintained and applied, some framework must be established to account for their anticipatory decisions. One way of doing this is by ratifying advance directives as legally binding on health care professionals (and patients). Manifestly, such a policy change will have stringent implications for both health care professionals and patients and we will analyze these implications in turn.

\section{Restriction of clinical freedom}

If anticipatory decisions are worthy of safe guarding, then advance directives exist not merely to express what a competent person would wish upon a particular contingency, namely the loss of competence, but to secure those wishes. If this was not the case, there would be little point in the present discussion since the expression of one's wishes in such prospective circumstances is usually accounted for by, for example, the current system of doctor-patient dialogue.

We recommend that the following principle be accepted and be used to govern and constrain the use of advance directives:

Where what I'm directing would normally be respected when I'm conscious and competent, the same respect should be shown my wishes as contained in an advance directive made when I am competent, even though it comes into effect when I am not.

This is the whole point of making an advance directive. And if these devices are to be recognized as worth the paper on which they are written, then this should be their effect, and except where the securing of such wishes conflicts with a clear public interest - such as where a person expresses a wish that their organs should not be utilized for the saving of another's life or the alleviation of another's suffering - this should be ratified by binding legislation. 12

This places a substantial constraint on what many understand by 'clinical freedom'. Put rather simplistically, in decision-making as to a course of treatment for a mentally incompetent patient, the doctor's hands are tied by that patient's previous instructions made when competent.

How serious a matter is this for the physician? Clearly, if the patient drafting an advance directive is to make informed choices as to what care to choose should he suffer loss of competence he will need to be appraised of the available treatment options and their respective prognoses. He will thus need to seek medical advice from his physician prior to drafting the directive. Whilst the physician can have no moral objection to providing relevant information to his/her patient (particularly if the patient is, for example, in the early stages of a dementing condition at the time of considering an advance directive), such consultation provides the physician with an opportunity to voice any conscientious objection he may have to, for example, withholding treatment in the event of loss of competence. Indeed, the physician should take the opportunity to make the patient aware that he would personally not be a party to the withholding or withdrawing of lifesustaining treatment. This initial doctor-patient dialogue thus allows the patient and physician to arrange to have the management of the patient's medical care consigned to another physician who does not hold any objections to the patient's chosen course.

\section{Resource allocation: 'hands-off' and 'hands-on' directives}

There is a seemingly obvious but, in the end, complex distinction to be drawn between two types of advance directive: 'hands-off' directives and 'hands-on' directives. The former are often thought to have no resource implications (except 'positive' - or 'neutral' - implications) in that they are directives instructing, for example, that of all the possible treatment options at the disposal of the doctor in the kind of situations we are talking 
about, none be administered. However, as will be obvious, even 'hands off' directives are almost never directives to do literally nothing. Even the instruction to desist from therapy will often leave the patient in need of palliative care and this can be prolonged and expensive. However, since hands off directives usually involve only the instruction to commit resources that would in any event have been committed had there existed no such directive, they can be effectively considered to have minimal resource implications. Hands-on directives, by contrast, can have considerable resource implications and if, for example, they include instructions requiring aggressive treatment, they may, if acceded to, distort equitable resource allocation.

Again, a principle for coping with this problem suggests itself:

Where there exists some reason for not granting my requests on grounds of scarce resources, I should be an equal competitor for those resources with the competent unless those resources cannot (literally) benefit me. *

Suppose, on the other hand, that a directive states that, in the event of the kind of situation we are envisaging, its author requires no aggressive medical intervention but palliative care only and that by the time the contingency arises a new treatment has been developed which could facilitate the patient's full recovery. This kind of example underscores the need for the author of the advance directive to take the matter seriously, seek full and open medical advice prior to the drafting of an advance directive, and to update that directive at regular intervals so as to account for therapeutic advances. It may, of course, be possible to draft directives sufficiently broadly to include provision for advances that are anticipated in their general effect, but not in their detailed science or mode of operation.

\footnotetext{
* As opposed to the situation where a doctor sees no benefit in prolonging a patient's existence for one week or one month, for example, and the patient himself is in disagreement about how much life-time is worthwhile. 13,14
}

\section{You can't have it both ways?}

And this raises another issue: should the author of an advance directive bear responsibility for its contents when these may have been in keeping with the then current state of the art in therapeutics at the time of its drafting, but which, at the time of its implementation is out of date and clearly not in line with the best interests of the patient? Whilst, in the interests of philosophical consistency, one may be tempted to answer in the affirmative, this is clearly to go against the spirit and primary aim of instituting advance directives. A less formalistic approach would be to account for the lack of circumspection of patients by providing the option of, or requiring, in addition to an advance directive, the nomination of a proxy or surrogate decision-maker, unless, of course, the advance directive specifically anticipates and rejects modification in the light of new techniques or therapies.

\section{Surrogate decision making}

Delegation of one's decisions to a 'health care proxy' (also referred to in the literature as a 'surrogate decision maker' or, in the United States, a 'durable power of attorney for health care' the establishment of enduring powers of attorney for health care is one of the options currently under consideration by the Law Commission in England) may be viewed as an alternative to a written advance directive. The proxy takes on the role of deciding if and what treatment an incompetent patient would have chosen for himself if competent. Clearly, these are decisions of great moment and the choice of a proxy should not be made lightly: the proxy should be someone who is familiar with the views of the nominator and whose conscience would not incline her to make decisions contrary to the nominator's wishes.

If the health care proxy acts in conjunction with an advance directive, the role of the proxy may be particularly significant where, for instance, a patient's advance directive was made some considerable time prior to his loss of competence, has not been updated in the intervening period, and is, at the time of incompetence, apparently irrelevant or inappropriate. Is what the proxy is entitled to ask for constrained in any way? The 
BMA views the role of the proxy as one of 'substituted judgement' whereby the incompetent patient's appointed agent acts as a 'sympathetic interpreter of the patient's own values, rather than attempting to judge the patient's best interests.' 1 Suppose, however, the proxy asks for a treatment which all others perceive as being against the patient's interest, e.g. he asks that a previously unenvisaged life-saving drug not be administered. The decision to take one's own life - and we are assuming here the moral symmetry of acts and omissions ${ }^{15}$ - must surely be that of the individual, not of his proxy. This suggests the necessity of a third line of defence of the patient's autonomy, whereby in situations where the proxy's interpretation of the patient's advance directive is clearly in error, or her interpretation of the patient's 'own values' are at odds with his best interests, there is recourse to, perhaps, a court of law or a legal tribunal. However, if advance directives are formulated with lucidity and if the choice of any proxy is made carefully, there will likely be only infrequent need for such recourse to the law.

\section{Optimal protection for anticipatory decisions?}

The BMA sees the advance directive and the use of the health care proxy as distinct devices ${ }^{1}$ whilst others distinguish between two types of advance directives, those which delineate the patient's treatment choices on loss of competence and those which serve to appoint a health care proxy. ${ }^{16}$ Most countenance the use of advance directives in combination with health care proxies. ${ }^{*}$

It is not always possible for the author of an advance directive to imagine or account for all future, possible exigencies, and those attempts at designing advance directives, such as the 'Medical Directive', 18 which provide exhaustive coverage of hypothetical contingencies tend to

\footnotetext{
* The living will developed by the Terrence Higgins Trust with the Centre of Medical Law and Ethics, King's College, London, for example, provides for this dual role. ${ }^{17}$ Note that whilst this particular living will was designed for use by those persons with HIV infection or AIDS, it is a model which has application to any mentally incapacitating condition.
}

be cumbersome documents, since the attempt to achieve specificity and comprehensiveness is at the expense of simplicity and clarity. And as medical technology progresses, we may expect a concomitant increase in the complexity of such documents as, to be effective, they will need to be continually updated with the patient's wishes regarding the use of new aggressive therapies as and when they become available.

Manifestly, any measure which aims to provide the greatest possible protection of the patient's autonomous health care choices must be practical and versatile. With this in mind, we would recommend a dual-purpose document which both lays out the patient's treatment preferences and appoints a health care proxy. One of the advantages, as we see it, of this combination instrument is that the statement of the patient's treatment preferences need not be a comprehensive account of his wishes in all imaginable contingencies. Rather, it should be a clear and considered statement of his personal values and general views regarding the sustaining of his life when mentally incompetent and a simple affirmation of his wishes for the withholding or curtailment of therapy in such a context - for example, whether his view would be different if the envisaged condition did not involve an irrevocable loss of competence but was one with a slim possibility of recovery, a coma perhaps.

With the general view of the patient so represented, the specific decisions regarding particular therapeutic interventions may be made by the appointed health care proxy. Clearly, not only must the author of an advanced directive of this kind be fully informed of the medical facts pertaining to contingencies involving loss of competence and the chances of recovery associated with various conditions prior to the drafting of the directive, but the proxy must be fully informed of the treatment options and their prognoses for the specific condition which has prompted the implementation of the directive at the time of its implementation.

Such a device places the health care proxy in a position of great responsibility. However, though the patient's views may be encapsulated in a simple statement, this is sufficient for the proxy to judge whether her treatment choices are in line with the patient's expressed values (if only by looking to the net effects of available treatment 
options) and for third parties to judge whether the proxy's decisions are in keeping with those values.

The necessity of updating the advance directive remains, but in view of the nature of this mechanism, updating is more to account for any change of view the directive's author may have over time than to accommodate therapeutic advances.

\section{A philosophical puzzle}

Let us end by posing and resolving a vexing philosophical question and one which might seem to undermine the philosophical justification for taking advance directives seriously. We have seen that advance directives embody protections for a person's autonomy. It seems fair to say that the capacity for autonomy involves the possession of abilities necessary for the exercise of selfdetermination. A permanent loss of competence, by definition, implies a loss of the capacity for autonomy. Thus, just as it is absurd to talk of the autonomy of the dead, is it not also absurd to speak of the protection of the autonomy of the mentally incompetent?

But to pose the question in this way, while creating a satisfying philosophical puzzle, misses an important point. People can have powerful interests of which they are not, nor need ever be, conscious. I have a powerful interest that my child be not tortured after my death although, because it never occurs to me that such a thing might happen, I never become conscious of this interest. Similarly, I may have such an interest in the manner of my death though, because I lose consciousness long before my death, I do not experience just how I die. Ronald Dworkin has called such interests 'critical interests'12,19 and has argued for their importance, not by showing that we are consciously adversely affected by their denial, but by explaining how they are connected with the sense we make of existence - with its integrity.

So it is not the autonomy of the unconscious we are protecting but their critical interest in having their autonomous decisions respected, even when they are no longer capable of making any such decisions or of being aware of whether or not they are being respected.

How important it is to respect critical interests as opposed to conscious interests, particularly when the conscious critical interests of some are in competition with the bare critical interests of others (as where my conscious critical interest in receiving a life-saving organ transplant is in competition with your advance directive not to have your organs used after your death) ${ }^{12}$ is a further and very vexed question. One certainly beyond the scope of this short discussion.

\section{Acknowledgement}

This paper is the result of ongoing research into advance directives in the context of HIV/AIDS as part of the development of the project for the Commission of the European Communities' Biomedical and Health Research Programme entitled 'AIDS: Ethics, Justice and European Policy'. The authors gratefully acknowledge the stimulus and support of the Commission.

\section{References}

1 British Medical Association. BMA statement on advance directives. London: BMA, 1992: 1-11.

2 In re Quinlan, 355 A2d 647, (NJ 1976).

3 High DM. 'All in the family: extended autonomy and expectations in surrogate health care decision making. Gerontologist 1988; 28: 46-51.

4 Cohen-Mansfield J, Droge JA, Billig N. Factors influencing hospital patients' preferences in the utilization of life-sustaining treatments. Gerontologist $1992 ; 32$ : 89-95.

5 Henderson M. Beyond the living will. Gerontologist 1990; 30: 480-85.

6 Miller T, Cugliari AM. Withdrawing and withholding treatment: policies in long-term care facilities.

Gerontologist 1990; 30: 462-68.

7 Diamond E, Jernigan JA, Mosely RA, Messina V, McKeown RA. Decision-making ability and advance directive preferences in nursing home patients and proxies. Gerontologist 1989; 29: 622-26.

8 Cruzan v Director, Missouri Department of Health, (SCt 1990), 497 US 261, 110 SCt 2841, 1990.

9 Cruzan v Harmon, Missouri Supreme Court, 760 SW2d 408, 1988.

10 Emanuel LL, Barry MJ, Stoeckle JD, Ettelson LM, Emanuel EJ. Advance directives for medical care - a case for greater use. $N$ Engl J Med 1991; 324: 889-95.

11 Gamble ER, McDonald PJ, Lichstein PR. Knowledge, attitudes, and behaviour of elderly persons regarding living wills. Arch Intern Med 1991; 151: $277-80$.

12 Harris J. Wonderwoman and superman: the ethics of human biotechnology. Oxford: Oxford University Press, 1992.

13 Harris J. The value of life: an introduction to medical 
ethics. London: Routledge and Kegan Paul, 1985.

14 Harris J. Does justice require that we be ageist? Bioethics 1994; 8: 74-84.

15 Harris J. Violence and responsibility. London: Routledge and Kegan Paul, 1980.

16 Wachter RM, Lo B. Advance directives for patients with human immunodeficiency virus infection. Crit Care Clin 1993; 9: 125-36.
17 The Terrence Higgins Trust and King's College London. Living will. London: Terrence Higgins Trust and King's College London, 1992.

18 Emanuel LL, Emanuel EJ. The medical directive: a new comprehensive advance care document. JAMA 1989; 261: 3288-93.

19 Dworkin R. Life's dominion. London: Harper Collins, 1993. 